\title{
EHLERS, Caspar, Metropolis Germaniae. Studien zur Bedeutung Speyers für das Königtum (751-1250)
}

\section{Pierre Monnet}

\section{OpenEdition}

\section{Journals}

Édition électronique

URL : http://journals.openedition.org/ifha/1508

DOI : $10.4000 /$ ifha. 1508

ISSN : 2198-8943

\section{Éditeur}

IFRA - Institut franco-allemand (sciences historiques et sociales)

\section{Référence électronique}

Pierre Monnet, «EHLERS, Caspar, Metropolis Germaniae. Studien zur Bedeutung Speyers für das Königtum (751-1250) », Revue de l'IFHA [En ligne], Date de recension, mis en ligne le 01 janvier 1997, consulté le 22 septembre 2020. URL : http://journals.openedition.org/ifha/1508 ; DOI : https://doi.org/ 10.4000/ifha.1508

Ce document a été généré automatiquement le 22 septembre 2020.

(C)IFHA 


\title{
EHLERS, Caspar, Metropolis Germaniae. Studien zur Bedeutung Speyers für das Königtum (751-1250)
}

\author{
Pierre Monnet
}

1 C'est dans le douzième livre de L'Histoire ecclésiastique d'Orderic Vital que Spire reçoit le qualificatif de Metropolis Germaniae. Ainsi que le montre de manière convaincante l'auteur, chercheur au Max-Planck-Institut für Geschichte, cette dénomination ne renvoie pas vraiment au siège épiscopal, d'autant que le métropolitain de Spire est l'archevêque de Mayence et que d'autres évêchés, sous la plume de l'auteur de l'Historia ecclesiastica, ne bénéficient pas de ce titre honorable. Pour l'auteur de cette étude, comme pour Orderic Vital lui-même, il s'agit bien plutôt d'une distinction qui signale une position privilégiée de la ville, un lien spécial entre Spire et la royauté qui provient en vérité de son statut de résidence et de nécropole royale. D’où vient cette relation, sur quoi repose-t-elle et quelle est la nature de la memoria royale qui s'y déploie: telles sont les questions principales auxquelles l'ouvrage entend apporter des éléments de réponse. La période observée est large: cinq siècles de monarchie des Carolingiens aux derniers Hohenstaufen, dynastie à partir de laquelle les liens ont commencé à se distendre puisque, en dehors d'Agnès et de Béatrice, Philippe de Souabe fut le seul souverain à y être enterré après, du reste, une première station à Bamberg. Il n'en demeure pas moins qu'avec 254 séjours royaux au total de 751 à 1250 , la ville de Spire, que les sources cessent d'appeler de son ancien nom romain Nemetum à partir du XIe s., attache son nom aux différents rois et empereurs qui en firent une résidence habituelle au cours de leurs fréquents déplacements. L'auteur pose bien la question très controversée de l'existence à Spire d'un palais proprement royal (Königspfalz). En l'absence de témoignages écrits probants et de preuves archéologiques, il est prudent d'en rester aux hypothèses: si le roi a bien toujours résidé dans un même lieu, il n'est pas sûr qu'il le possédait en propre et il fut peut-être alors l'hôte de l'évêque. La chronologie des visites royales et leur répartition, selon qu'il s'agissait de brefs séjours au hasard d'un itinéraire ou d'une station plus longue et plus politique (par exemple liée à la présence d'autres princes ou à la tenue d'une diète), montrent assurément que 
le lien privilégié entre Spire et la royauté s'est établi sous la dynastie des Saliens qui firent de la cathédrale, objet de leur sollicitude puisqu'elle fut alors restaurée et agrandie, une véritable nécropole royale qui permit une "concentration de la memoria salienne«. Le point de départ de toute cette entreprise semble bien être le règne de Conrad II, lequel fut enterré en grande cérémonie dans la cathédrale en 1039. La participation de la reine Gisela à cette volonté manifeste autorise l'auteur à parler d'un couple de fondateurs (Stifterpaar). Henri III, Henri IV et Henri V à leur tour y placèrent leurs tombeaux à côté de ceux de leurs fils, filles et épouses. Sur ces fondements se serait dressé, à une date que l'auteur place postérieurement à 1125 , un véritable "mausolée« des Saliens glorifiant la mémoire de ces morts illustres, un monument disparu qui n'est cependant attesté que par une seule source manuscrite, celle de Burchard von Ursperg des années $1220 .$. Quoi qu'il en soit, on ne retrouve assurément pas une telle faveur sous les Staufen, encore que ces derniers, qui eurent à coeur de se poser en dignes héritiers des Saliens, continuèrent à célébrer activement les messes anniversaires de leurs prédécesseurs comme l'attestent les nécrologues dont l'ouvrage fait une présentation approfondie. Par dessus les tombeaux de Spire continuait donc d'agir la force de la memoria royale qui avait même fini par trouver un relais chez les souveraines puisque Agnès et Béatrice vinrent reposer dans le choeur de la cathédrale, enrichissant par leur présence silencieuse la communauté de prière qui unissait ces frères et soeurs illustres aux chanoines du chapitre en un Gebetsbund que C.E. prend bien soin de distinguer d'un Königskanonikat. C'est bien d'ailleurs par cette confrérie de la prière que la memoria salienne s'est trouvée entretenue et poursuivie sous les Hohenstaufen. Reste à savoir pourquoi précisément cette dynastie n'a pas tenu à transformer Spire en véritable sanctuaire de la monarchie sur un »modèle« capétien. Seule cette question, dans un livre très riche et très touffu, demeure sans réponse. Il est vrai qu'elle eût obligé l'auteur à mener une étude comparatiste qui pose forcément d'autres problèmes que ceux qui ont retenu son attention. Mais il n'était pas interdit d'ouvrir du moins des perspectives qui eussent permis, par exemple, d'enrichir la bibliographie de quelques titres consacrés à Saint-Denis. En dépit de ce reproche, bien minime et très "français«, les spécialistes trouveront dans ce livre une étude très riche et très originale qui montre que l'histoire politique ne cesse de se renouveler grâce à l'apport de nouvelles lectures qui croisent à la fois l'histoire urbaine (on pense en particulier aux belles pages qui insistent sur l'intégration des habitants laïcs de la ville dans la commémoration de la messe anniversaire par le privilège de 1111), l'histoire culturelle, celle de l'idéologie et des symboles du pouvoir et la problématique de la memoria. 